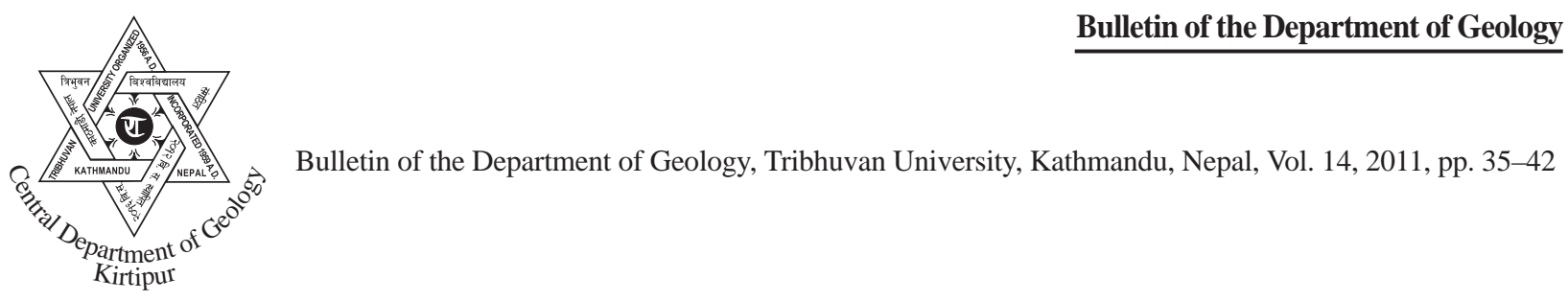

\title{
Paleolimnology of Lake Yamanaka as reflected on particle-size distribution
}

\author{
Danda Pani Adhikari \\ Department of Geology, Tri-Chandra Campus, Ghantaghar, Kathmandu, Nepal
}

\begin{abstract}
A $17.63 \mathrm{~m}$ long bore-hole core extracted from the deepest part of Lake Yamanaka, one of the Fuji-five Lakes at the northeastern foot of Mount Fuji, central Japan, composed of sediment with intercalations of scoria fallout deposits. The sediment of the upper $11.4 \mathrm{~m}$ was investigated for grain-size distribution by using a laser diffraction particle size analyser. The mean grain-size profile showed various degrees of fluctuations, both short-and long-terms, and the size-frequency distribution revealed unimodal-trimodal mixing of sediments. Changes in lake size and water depth appear to be the main factors affecting the variability in the grain-size distribution and properties. The lake level appears low during 7000-5000 cal BP and 2800-1150 cal BP and relatively high during 5000-2800 cal BP and $1150 \mathrm{cal} \mathrm{BP}-$ present.
\end{abstract}

\section{INTRODUCTION}

Fuji-five Lakes (Lake Yamanaka, Lake Kawaguchi, Lake Sai, Lake Shoji, and Lake Motoshu), popularly known by Fuji-Goko in Japanese, arched the northern side of Mount Fuji (Fig. 1). Among the five lakes, Lake Yamanaka, the most easterly located lake and object of the present study, is the largest (surface area $6.9 \mathrm{~km}^{2}$ ), highest in elevation (981 m) and closest to Mount Fuji (Fig.1). With a circumference of 13.6 km, the basin floor of the lake roughly makes a crescentshape with concave side facing toward south (Fig. 2). The maximum length, width, and depth are $6 \mathrm{~km}$ and $2 \mathrm{~km}$, and $14.3 \mathrm{~m}$, respectively (Fig. 2). Drainage basin of the lake covers $62.1 \mathrm{~km}^{2}$ areas, which is mostly vegetated except some barren surface in the uppermost part of the catchment in the slope of Mt. Fuji (Fig. 3).

Sedimentary and hydrological processes in the catchment area of Lake Yamanaka, as evident from its position, are under the influence of the volcanic activity of Mt Fuji, which started its eruption ca. 100,000 years ago (Miyaji et al., 1988). Historically, 10 eruptions are reported since $\mathrm{AD} 781$, and the $\mathrm{AD}$ 1707 event, which is known by Hoêi-eruption, was

\footnotetext{
*Corresponding author:

E-mail address: adhikaridp@ntc.net.np
}

the most recent. In the catchment of Lake Yamanaka, the eastern and southeastern parts consist largely of undifferentiated volcanic ejecta of Younger Fuji Volcano (YFV) (Figs. 1 and 3), whereas the high-elevation catchment area in the north consists of Quartz diorite, and the Tertiary marine sedimentary rocks (Misaka Group) crop out in the lower mountain slopes. Deposits of pyroclastic fall and flow, and debris flow of YFV, and mudflow of Older Fuji Volcano (OFV) are widespread up to the middle reaches in the southeastern part; the upper steeper slopes in this part consist of younger lava flows. Around the western end, including lake outlet area, Takmarubi lava crops out on the surface.

The lake has a few streams (Fig. 2) and none of which has usual surface flow except during occasional torrential rain events in summer and typhoon seasons and sudden snow melt in spring. It is because the surface materials are highly permeable and water on the surface easily percolates down and flows to the lake through subsurface paths (Koshimizu and Tomura, 2000). Koshimizu and Uchiyama (2002) described the volcanic history of Mt. Fuji based on a bore-hole core $(17.63 \mathrm{~m})$ taken from Lake Yamanaka; and later, Yoshizawa et al. (2004) studied diatoms in the sediment and reported the existence of four major shifts in the assemblage composition. However, sediments of the 


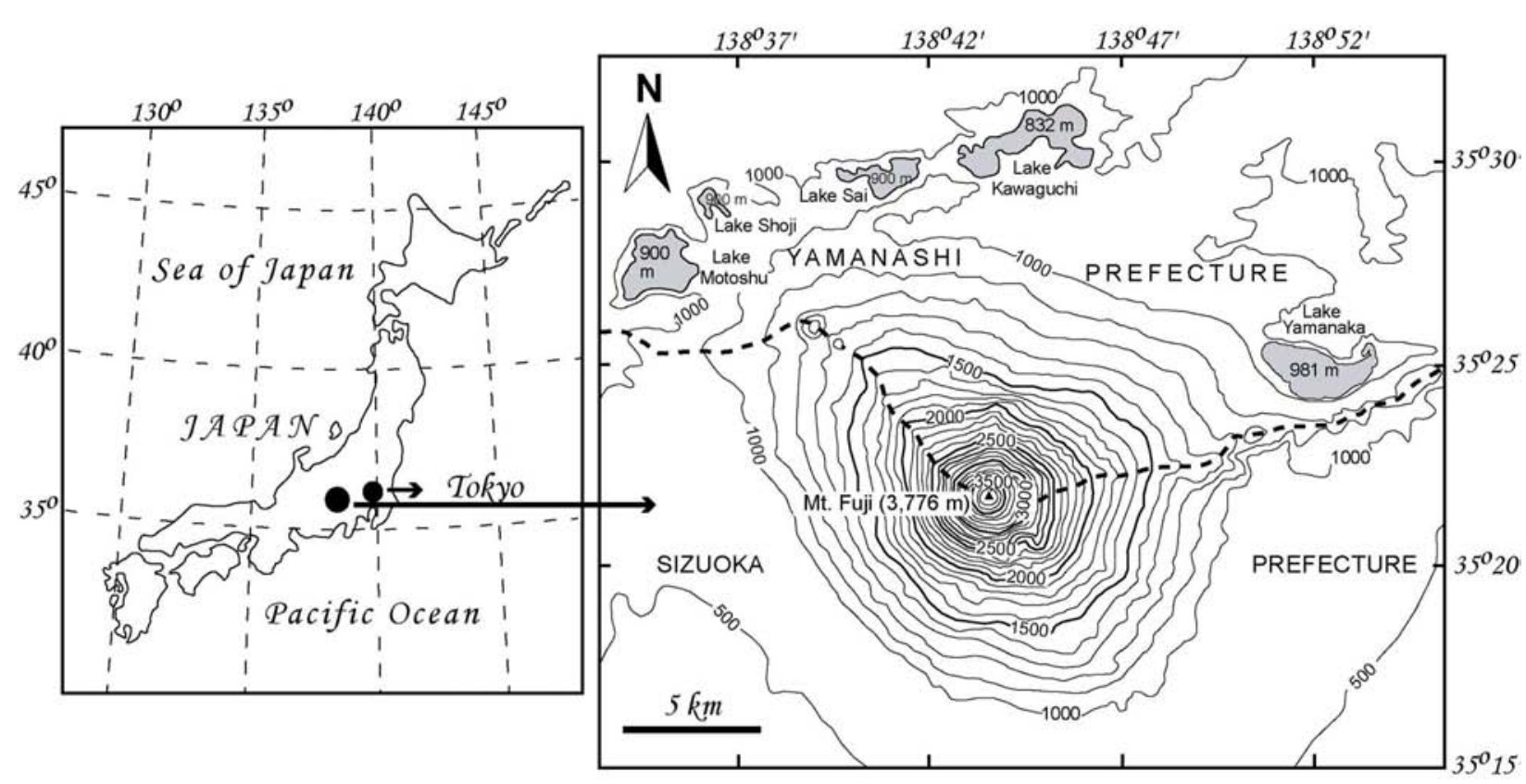

Fig. 1 Location of the Fuji-five Lakes and Lake Yamanaka in Japan. Topographic features of the region, including Mt. Fuji are also shown. Contour values are in meter.

lake have not yet been analysed for grain-size, whereas it could reveal important information about the lake history and sedimentary process-paleolimnology. This paper presents results of variation in mean grain-size and size frequency distribution in the sediment-cores, and interprets the observed variations as function of water depth and distance from the shore line.

\section{MATERIALS AND METHODS}

A $17.65 \mathrm{~m}$ long bore-hole core, comprising both sediments and pyroclastic fall deposits, was extracted from the deepest part of the lake (Fig. 2) previously by Koshimizu and Uchiyama (2002). Sediments from the upper $11.4 \mathrm{~m}$ were sampled at an intervals of 1-3 $\mathrm{cm}$ and investigated for grain-size by using a laser diffraction particle size analyzer (SALD-3000J, Shimadzu), which utilizes grain-size range, 0.1-2000 $\mu \mathrm{m}$.

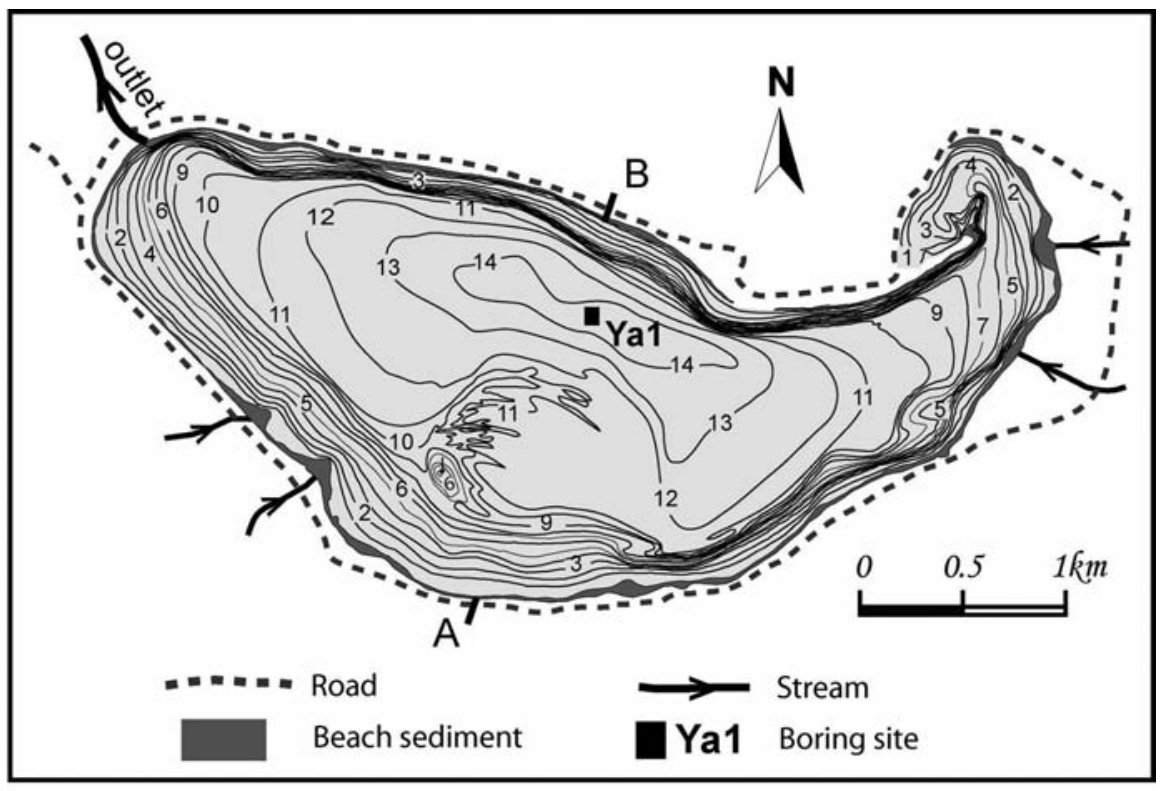

Fig. 2 Bathymetric map of Lake Yamanaka with the location of coring site. Water depths are in meter. 


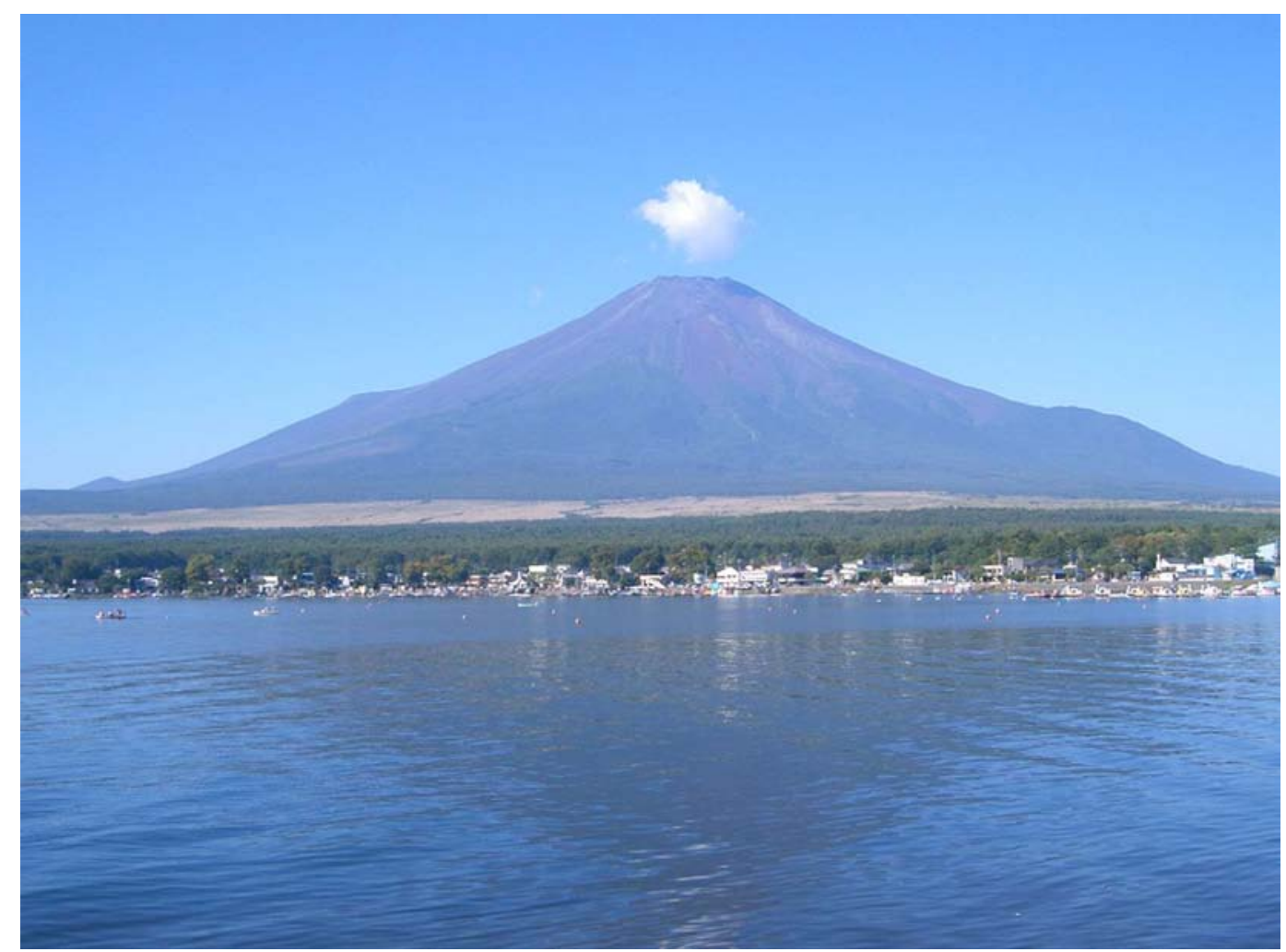

Fig. 3 Mt. Fuji and Lake Yamanaka on the fore ground. The lake is on the northern side of the mountain.

Particles coarser than $2 \mathrm{~mm}$, if any, were therefore removed and the remaining samples were treated with $30 \% \mathrm{H}_{2} \mathrm{O}_{2}$ to remove organic matters. Samples were then dispersed with $5.5 \mathrm{~g} / \mathrm{l}$ sodium hexametaphosphate (Calgon) for a minimum of $24 \mathrm{hrs,} \mathrm{but} \mathrm{not} \mathrm{for} \mathrm{more}$ than 5 days. The samples were further dispersed via 10 minutes of exposure in an ultrasonic bath just before size analysis. For the purpose of particle-size specification, the following scale used by Folk and Ward (1957) was adopted; granule: $>2 \mathrm{~mm}$, sand: $2000-63 \mu \mathrm{m}(-1$ to $4 \phi)$, silt: $63-3.9 \mu \mathrm{m}(4-8 \phi)$, clay: 3.9-0.24 $\mu \mathrm{m}(8-12 \phi)$, and colloid: $<0.24 \mu \mathrm{m}(>12$ $\phi)$. Sorting, a measure of the degree of spread of grainsizes around the mean value was calculated following the statistical formula of Folk and Ward (1957). Verbal sorting description was: poorly sorted for $1-2 \phi$, and very poorly sorted for $2-4 \phi$.

Radiocarbon dating of the sediments was performed for three plant materials using a standard Accelerator Mass Spectrometer (AMS) method at the Beta Analytical Radiocarbon Dating Laboratory, Japan. The volcanic ash layer at $82 \mathrm{~cm}$ depth is correlated with the known marker tephra of Hoêi-eruption (AD 1707) and that provided age control for the upper part of the core. Sediment chronology was derived from those three radiocarbon and one volcanic ash dates, and the ages were calibrated to calendar years.

\section{RESULTS}

The core below $11.4 \mathrm{~m}$ was of entirely scoria fallout deposits, and above this depth the core was characterized by $669 \mathrm{~cm}$ sediments with intercalations of scoria fallout (28 horizons, $451 \mathrm{~cm})$ and debris flow $(20 \mathrm{~cm})$ deposits (Fig. 4). The 28 scoria fallout horizons indicate that there were at least 28 volcanic events in the 7000 years history of Lake Yamanaka sediment. Thickness of scoria horizons varied from 2 to $62 \mathrm{~cm}$, and the individual particles were of lapilli size (2-64 mm). All the scoria and debris flow deposits (event material deposited in very short time) were excluded for further analysis and the remaining sediments as shown in Fig. 5 a were analysed for their grain-size.

The mean grain-size of the sediment showed variations from $7 \phi(7.8 \mu \mathrm{m})$-fine silt to $3 \phi(125 \mu \mathrm{m})$ -fine sand (Fig. 5b). In these variations, both short and long - terms fluctuations and their abrupt transitions were evident. In overall, sediment particle-size distributions showed poor to very poor sorting, and generally sorting deteriorated with increasing mean 


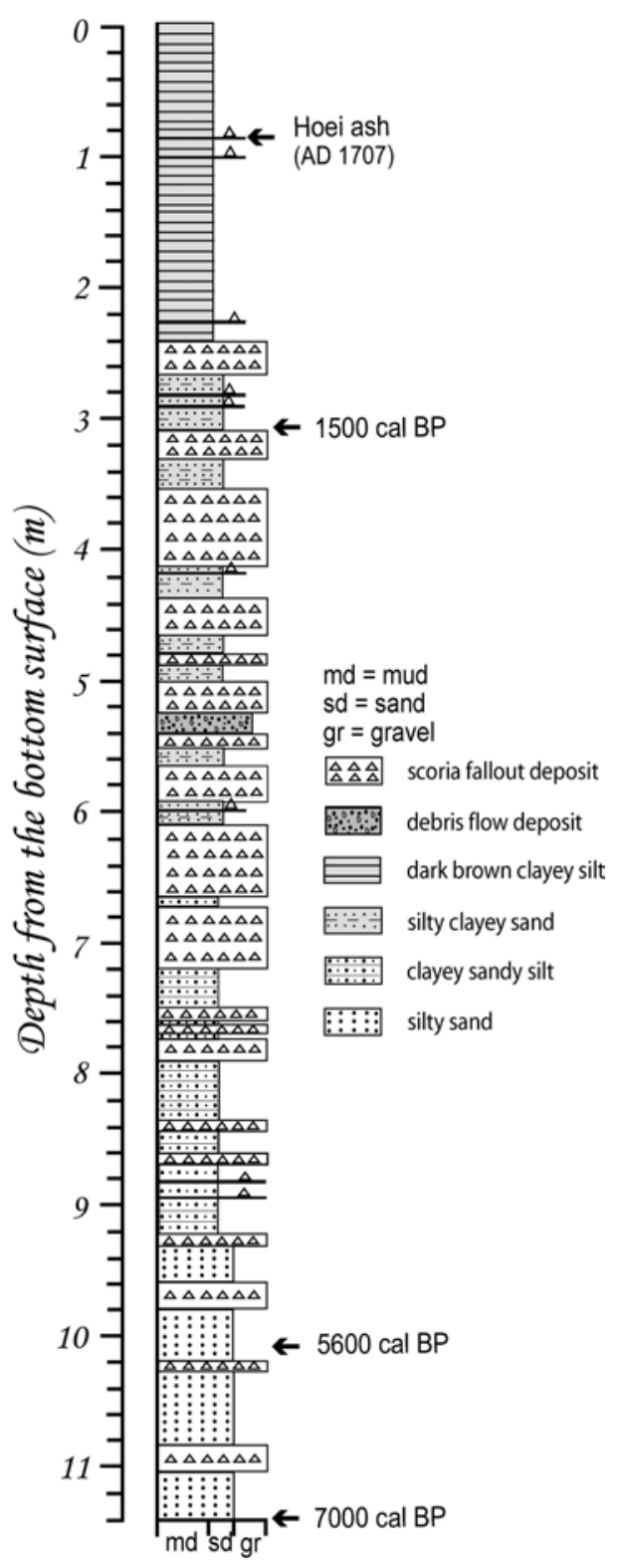

Fig. 4 Lithologic column of the boring core with lake sediments and event (scoria fallout and debris flow) deposits. Dated horizons are shown with calibrated age.

grain-size (Fig. 6). The distribution provided varieties of size-frequency curves, comprising unimodal, bimodal and trimodal populations in sand or silt size (Fig.7). Each mode was within itself nearly symmetrical, but variation in sorting within a sample was high due to the introduction of excess of materials in the tail of the distribution curve. Based on the patterns of long-term fluctuations in mean grain-size combined with the variation in size-frequency distributions, the whole sediment record is divided

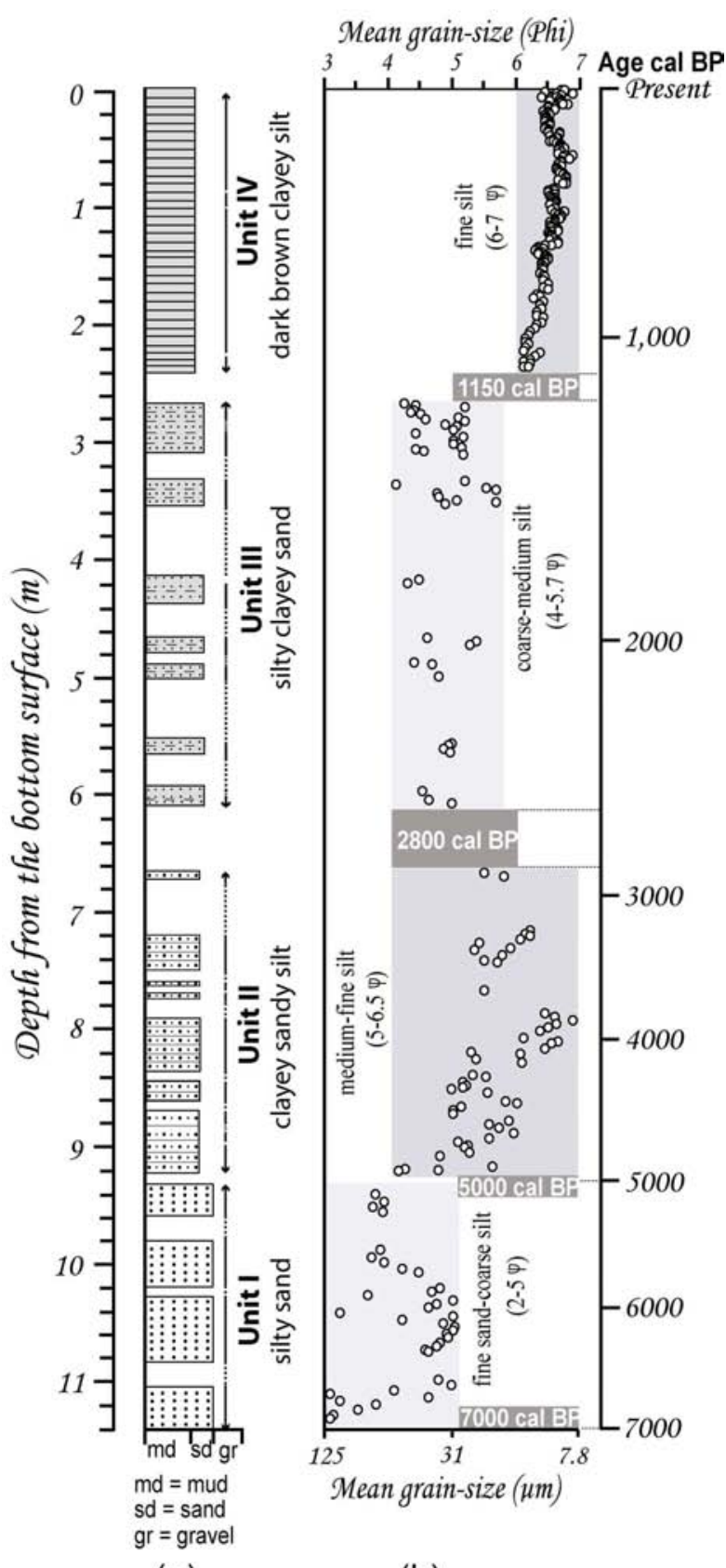

(a)

(b)

Fig. 5 (a) Lithologic column of the boring core excluding the event deposits shown in Fig. 4, and (b) Variation in the mean grain-size of the lake sediments with depth. Division of the column into units I-IV are based on the nature of the sediments and long-term variation in the mean grain-size.

into four subdivisions as units I, II, III and IV (Fig. 6) and described below, separately.

Unit I: The sediment between 1140 and $933 \mathrm{~cm}$ (unit I) was silty sand with mean grain-size in fine 


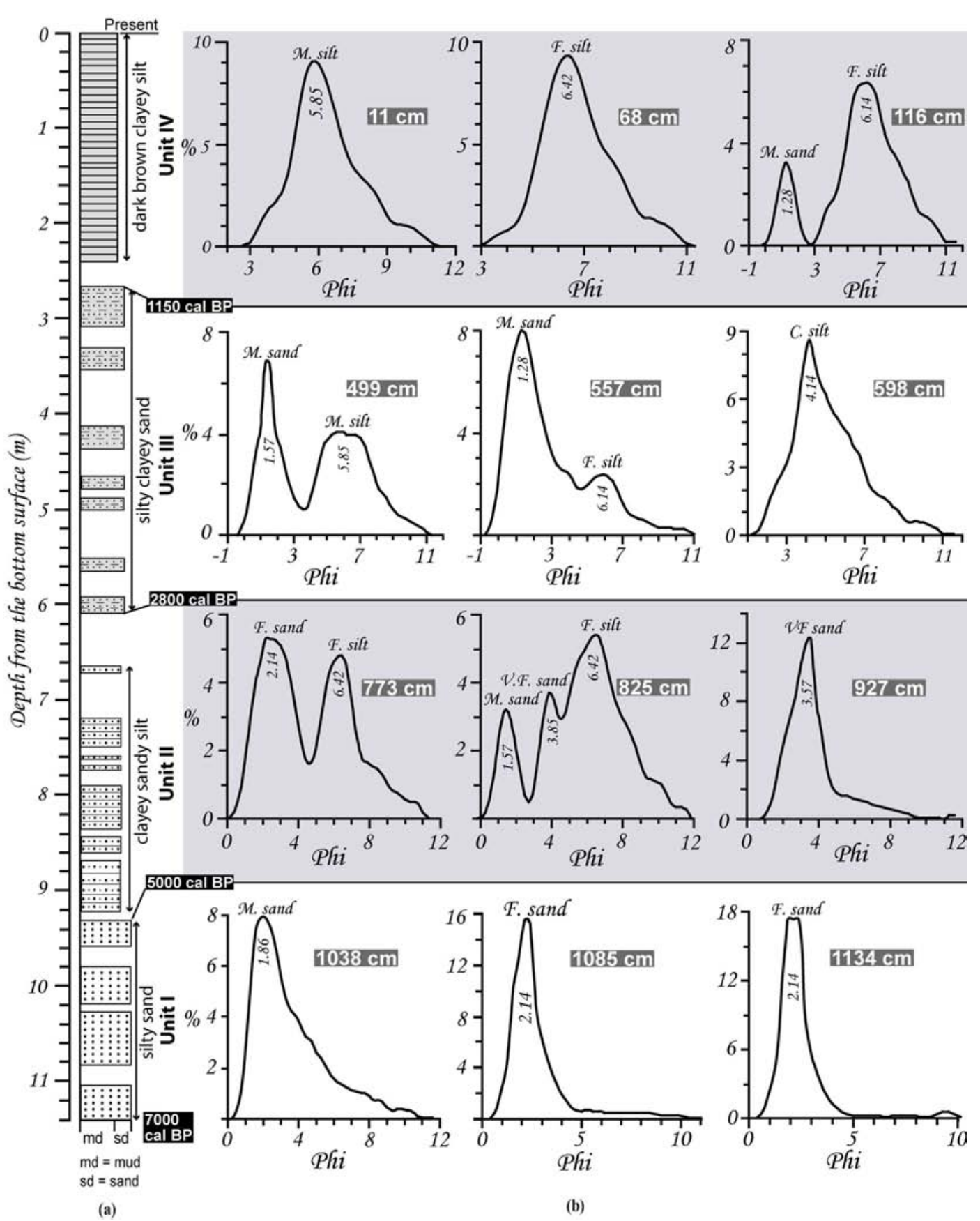

Fig. 6 (a) Lithologic column of the boring core excluding the event deposits, and (b) Representative size-frequency curves with indications of modal sizes in all the four (I-IV) units. Like the variation in mean grain-size in Fig. 6b, nature of size-frequency distribution is different in each unit. Age boundaries for each unit are also shown.

sand-coarse silt range $(2-5 \phi)$ (Fig. $5 b)$. It was characterized by the dominance of sand-sized particles, composing a pronounced, either medium $(1.86 \phi)$ or fine $(2.14 \phi)$ sand mode with a fine tail (Fig. 6b). The content of an excess of silt and clay produced a deviation from the normal distribution curve. Overall, the sediment was poorly to very poorly sorted (sorting,
$1.8-2.3 \phi$ ), indicating large range in particle size distribution.

Unit II: The sediment in unit II $(933-610 \mathrm{~cm})$ was clayey sandy silt with mean grain-size in the range between medium and fine silt (5-6.5 $\phi)$. Except the lowermost few centimeters (e.g., $927 \mathrm{~cm}$ in Fig. 6b), 
the sediment in this unit represented bimodal or trimodal mixing of particles from medium sand to fine silt size in different proportions. The sediment was poorly sorted (sorting, 1.27-1.9 $\phi$ ), but the degree of sorting was slightly better than in unit I.

Unit III: Unit III (610-240 cm) was silty Fig.4 (a) Lithologic column excluding the event sediments shown in Fig. 3a. (b) Representative size-frequency curves with indications of modal sizes in all the four (I-IV) units. Like the variation in mean grain-size in Fig. 3b, nature of size-frequency distribution is different in each unit. Age boundaries for each unit similar to Fig. 3 are also shown.

Clayey sand and the mean grain-size varied between coarse and medium silt (4.0-5.7 $\phi$ ) (Fig. 5b). The sizefrequency distribution showed unimodal or bimodal mixing of sand and silt, but unlike in unit II, no samples had trimodal distribution (Fig. 6b). Sorting was from poor to very poor (1.9-2.3).

Unit IV: The uppermost part of the core, above $240 \mathrm{~cm}$, comprised dark brown clayey silt with some sandy horizons; and the sediment sometimes contained randomly scattered dense granules. Mean grain-size was within fine silt (6-7 $\phi)$ range, which is the finest size in the whole profile (Fig. 5). The sediment generally consisted of a pronounced mode of medium $(5.85 \phi)$ or fine $(6.42 \phi)$ silt, and the distributions were nearly symmetrical; but the size-frequency curves in some horizons showed bimodal distribution, a major silt mode with a minor sand mode at the coarser end (e.g., $116 \mathrm{~cm}$ in Fig. 6b). The Sediment was poorly sorted (sorting, 1.2-1.7 $\phi$ ), but represented the best sorting in the whole record.

\section{DISCUSSION}

In the present day environment in Lake Yamanaka and other lacustrine setting (e.g., Adhikari \& Kumon, 2001; Digerfeldt, 1986), sand dominated sediments like that described in unit I above are deposited under shallow water close to the shore line (Fig. 7a). Analogous to that, the silty sand in unit I (Fig. 5a) can be interpreted as the shallow water deposit, but the presence of fine tails of silt and clay (Fig. 6b) and the associated very poor sorting suggest sediment reworking process was occurred in the lake after deposition and part of the fine particles left lake through suspension (Fig.7). Such reworking usually happens in shallow water environment and is of less significant to separate fines from coarse fraction.
Given the nature of the sediment in this unit, it is considered that currents and waves activities induced from the stream flow and wind stress to the water surface was not strong enough to winnow and sort the sediment because the inflowing streams and impounding water body were small, and because sufficient sediment dispersion could not occur due to short distance between lake center and the shore line. Sediments coarser than coarse silt would have deposited by bed load transport mechanism and the finer particles distributed in the tail were through suspension fallout process. Based on the above reasoning, the sediment spanning 7000-5000 cal BP (1140-933 cm) (Fig 7) represents deposit under shallow water environment as shown in Fig. 8a. It is reasonable to assume that, it was a transition from river to lacustrine phase. Location of such coarse, unimodal sediments (unit I) at the deepest part of the present lake is used as the reference to understand the position of the shore line or size of the lake through time.

A sudden decrease in the mean grain-size combined with the prevalence of bimodal and trimodal sizefrequency distribution and small improvement in sorting in unit II (Figs. 5, 6 and 7) may suggest wider and deeper lake as illustrated in Fig. 8b. As the lake widened, the distance between the shoreline and the sediment focusing center increased and the sediment reached to the center became finer (Fig. 8b). Spreading of sediments in a larger area and water body provided sorting energy to some extents even if the size of the inflowing streams were similar to that of during 7000-5000 cal BP. As a result, the sediment transported by different mechanisms (e.g., bed load, suspension, intermittent suspension) retained their individual characteristics reflecting multimodality in sizefrequency distribution. The nature of the up core fining in particle-size from unit I to unit II may therefore suggest a relatively deep water environment during 5000-2800 cal BP, but the unimodal size-distribution at the bottom part (927 cm in Fig. $7 \mathrm{~b}$,) may hint that the lake level raised slowly.

In accordance with the hydraulic interpretation made in units I and II, the coarsening of mean grainsize from medium-fine silt in unit II to coarse-medium silt in unit III, combined with the deterioration of sorting in Unit III (Figs. 5 and 7), it is interpreted as small and shallow lake again as in unit I and Fig. 7a. In response to the reduced lake size, the distance between the shore line and focusing center shortened as in unit I and the sediment became coarser. However, the smaller mean-size and multimodality in size- 


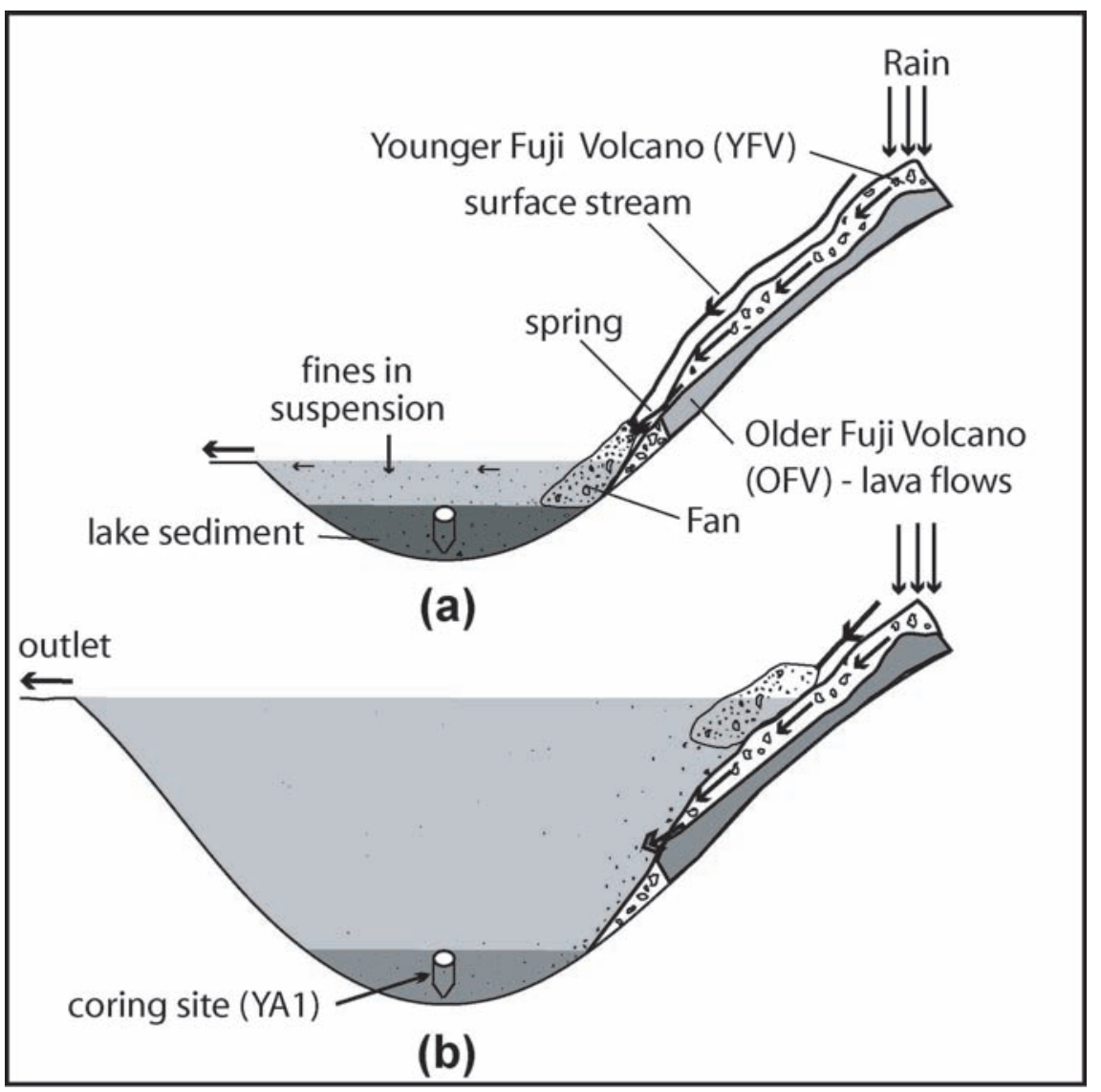

Fig.7 (a) Schematic diagram representing sedimentation pattern under low lake level condition, and (b) High lake level condition. Under low condition, the distance between lake center and shore line is smaller and fine particle leaves the lake through suspension making the sediment composition coarser. It is opposite under high lake condition.

distribution in unit III may suggest that the lake size during $2800-1150$ cal BP would be bigger than that during 7000-5000 cal BP.

Following the low stand during $2800-1150 \mathrm{cal}$ BP, the abrupt fining in sediments and modal composition (Figs. 5 \& 6b), combined with the improvement in sorting, can again be interpreted as return to a wide and deep lake as illustrated in Fig. 7b after $1150 \mathrm{cal}$ BP (800 AD). Though poorly sorted in absolute term, the occurrence of the finest sediment with the best sorting in the Yamanaka sediment record after 1150 cal BP may indicate the highest water depth never attained before in the lake history. The nearly symmetrical grain-size distribution curves on other hand indicates only one and consistent transport process, most probably suspension, occurred as bed load transport mechanism did not occur due to its remoteness from the shore line. The sand fraction, appearing as a separate mode in some samples would have mixed with the silt under increased stream flow conditions during rainstorm. There were no evidences of turbidity flow deposits throughout the sediment record.

Lake Yamanaka where renewed volcanic activities occurred in the catchment area, interpretation of its sediment grain-size variation with time needs precautions. It is because in the aftermath of eruptions, large volumes of volcanic debris could have reworked in the catchment and discharged into the lake. Thus, the sedimentary response to the eruption may reflect changes in sediment yield and grain-size that shows an increased input of volcaniclastic sediment after the eruption and that may follow by a decrease with the passage of time. However, the scoria horizons are mainly of primary pyroclastic-fall deposits rather than reworked volcaniclastic deposits. The dominance of scoria implies that it was probably derived from winddriven plinian type eruption, and the possibility of reworking was minimum as the streams draining into the lake are too small. 
Despite the possible influence of volcanic activity in the sediment grain-size variation, the given high magnitude, abrupt increase or decrease in the mean grain-size and the trend lasting for more than a millennium (Figs. $5 \& 6$ ) could be largely controlled by changes in lake size and water level rather than only by the catchment related change. The short-term fluctuations in the mean grain-size within each unit (Fig. 5b) are likely due to the influence of renewed volcanic activities, which changed availability of materials in the catchment. The proposed fluctuations in lake level could be due to blocking of river course by debris and lava flows from Mt. Fuji. Debris could originate either from volcanic or fluvial processes, and with passage of time, it could wash away by wave action and outlet erosion and result into lake level decrease. Cycles of such geomorphic processes occurring four times would have been responsible for the lake level fluctuations.

\section{CONCLUSIONS}

The occurrence of silty sand at the bottom of the lacustrine sequence provides basis for the understanding of the change in depositional environment with respect to change in the lake level and size. The depth-sensitive environments are distinguished by deposits with characteristic lithology. The long-term variation in mean grain-size is attributed to the deposition in variable water depths. The proximity of the coring site from the lake shore controls the process of the sedimentation, and is reflected in the size frequency distribution. The grain-size data reveals that the lake has a history of low- and high-stands, each two times, with corresponding decrease or increase in the lake size. Following the inception ca. $7000 \mathrm{cal} \mathrm{BP}$, the lake water level remains low until $5000 \mathrm{cal} \mathrm{BP}$ and an elevated water level is expected during 5000-2800 cal BP. Second low stand occurs during 2800-1150 cal BP and the second high-stand or the highest lake level in the record appears since $1150 \mathrm{cal} \mathrm{BP}(800$ AD). The fluctuations in size and depth of lake might have occurred in response to damming of lake outlet by debris or lava flow from Mt. Fuji and that followed by erosion with passage of time.

\section{ACKNOWLEDGEMENT}

The Japan Society for the Promotion of Science (JSPS) fellowship for research at the Yamanashi Institute of Environmental Sciences, Japan during 2003-2005 is gratefully acknowledged. The author is grateful to N. K. Tamrakar, Central Department of Geology, Tribhuvan University, Nepal for his constructive comments.

\section{REFERENCES}

Adhikari, D. P.and Kumon, F., 2001. Climatic changes during the past 1300 years as deduced from the sediments of Lake Nakatsuna, central Japan. Limnology, v.2, pp.157-168. http://dx.doi.org/10.1007/s10201-001-8031-7

Digerfeldt, G (1986): Studies on past lake-level fluctuations. In B. E. Berglund (Ed.), Handbook of Holocene Palaeoecology and Palaeohydrology. New York, Wiley, pp 127-143.

Folk, R.F. and Ward, W.C., 1957, Brazos River bar, a study in the significance of grain-size parameters. Jour. Sediment. Petro., v.27, pp. 3-26.

Koshimizu, S. and Uchiyama T., 2002, Geological outline of the borehole cores from Fuji-Five Lakes surrounding Mt. Fuji, central Japan. Daishiki, v.34, pp. 9-18.

Koshimizu, S. and Tomura, K., 2000. Geochemical behavior of trace vanadium in the spring, groundwater and lake water at the foot of Mt. Fuji, central Japan. In K Sato and Y. Iwasa, (Eds.), Groundwater Updates. Springer-Verlag Tokyo, pp 171-176.

Miyaji, N., 1988. History of younger Fuji volcano. Jour. Geol. Soc. Japan, v. 94, pp. 433-452.

Yoshizawa. K., Koshimizu, S. and Uchiyama, T., 2004. Environmental changes based on diatom assemblages from Lake Yamanaka at the northern foot of Mt. Fuji, central Japan. Research Report of Research and Education Center for Inlandwater Environment, Shinshu University, Proceeding of the 11th International Symposium on River and Lake Environments v.2, pp 105-110. 